\title{
Implementation of a Novel Multi-Agent System for Demand Response Management in Low-Voltage Distribution Networks
}

\author{
Sima Davarzani ${ }^{1, *}$, Ramon Granell $^{1,2}$, Gareth A. Taylor $^{1}$, Ioana Pisica ${ }^{1}$
}

${ }^{\prime}$ Brunel Institute of Energy Future, Brunel University London, Uxbridge, UB8 3PH

'Oxford e-Research Centre, Department of Engineering Science

\begin{abstract}
In this era of advanced distribution automation technologies, demand response is becoming an important tool for electricity network management. The available flexible loads can efficiently help in alleviating the network constraints and achieving demand-supply balance. Therefore, this forms the rationale behind this paper, which aims to implement a multi-agent system framework in order to achieve flexible price-based demand response. A genetic algorithm-based multi-objective optimization technique is applied to determine the optimal locations and the amount of required demand reduction in order to keep the network within statutory limits. The methodology is based on probabilistic estimation of the granularity of total available flexible demand from shiftable home appliances in each low-voltage feeder. Moreover, an optimal decision making for the start time of appliances upon receiving a real-time price signal is proposed. This is accomplished by considering the willingness to participate as well as price demand elasticity of the different clusters of customers. To fully demonstrate the feasibility and effectiveness of the proposed framework, a modified IEEE 69 bus distribution network comprising 1824 low voltage residential customers has been implemented and analyzed.
\end{abstract}

Keywords

Demand response (DR), multi-agent system (MAS), dynamic pricing, residential flexible demand, distribution networks, active network management (ANM).

\section{Nomenclature}

ap, AP Index and set of appliances in a home.

Sh Set of shiftable appliances in a home.

$\mathrm{t}, \mathrm{T} \quad$ Index and set of time intervals.

$\mathrm{h}, \mathrm{H} \quad$ Index and set of customers.

c, $\mathrm{C} \quad$ Index and set of cluster of customers.

$\mathrm{n}, \mathrm{NB} \quad$ Index and set of MV buses.

lb, LB Index and set of LV buses.

$\mathrm{br}, \mathrm{BR} \quad$ Index and set of MV branches. 


\section{Introduction}

The power flow at the Distribution Networks (DNs) is limited by several constraints. Voltage and thermal limits are among the most prominent ones. Increased penetration of intermittent distributed generation, such as wind and solar, in conjunction with potentially flexible loads, such as plug-in electric vehicles, can push the DNs to their capacity limit and hence introduce significant challenges for optimizing network use [1]. Exceeding network constraints boundary causes operational problems in the DN due to periods of extensive demand level. Therefore, there is a need to upgrade traditional DNs towards more intelligent platforms for controlling and coordinating these new loads and generations. In the low carbon future, Active Distribution Network Management (ADNM) with an interactive Low Voltage (LV) network is a key to unlocking the full potential of grid flexibility. The ADNM platform will host grid optimization algorithms, flexibility services and future innovation projects aiming to increase the utilization rate of existing network.

In the attempt to provide a smart and active DN in Great Britain (GB), the traditional passive managing role of Distribution Network Operators (DNOs) is now changing to Distribution System Operators (DSOs) [2]. Accordingly, a more decentralized approach is required for the management of DNs, where the introduction of System Operators (SO) at the local distribution level of the network becomes crucial. Recent technological advancements have provided significant opportunities to develop greater flexibility with regards to Demand Response (DR). Consequently, DR programmes have been introduced as effective and economic tools to enable power balancing across power networks and as a result, deferring or even avoiding DN's upgrading costs [3].

The effectiveness of employing DR from flexible resources in DNs as an alternative solution to reduce overall cost, improve network capability and flexibility, as well as delay future network investments, has been proven by a number of innovation pilot projects [4]. Consumers can also benefit from these schemes through reduction in their electricity bill. The Customer Load Active System Services project [5] resulted in up to 3.3GW of DR potential to provide voltage/frequency support which is equivalent to a combined total reactive power of $2 \mathrm{GVAr}$ and two gas turbine power plants. In another trial, the Accelerating Renewable Connections [6] combined an ADNM scheme and local community engagement to manage the generation-supply by generators and locally-produced energy sources respectively. This project enabled connection of 49.5MW and 2.2MW from wind farm and PV panels respectively into local homes. This could save households around $£ 1.9$ million in energy costs over the lifetime of the systems. However, except for rather small-scale trials, the implementation of DR in the DNs of GB has been very limited so far.

An optimal strategy for energy dispatch and pricing demonstrates the significant improvement in profits and load factors while reducing peak loads and environmental impact [7]. A novel framework for assessment of business cases for smart distributed multi-energy systems in a transactive energy context has been developed in [8]. A dynamic pricing DR algorithm for energy management has been introduced in [9] based on a hierarchical electricity market that considers both service provider's and customers' profits. Real Time Pricing (RTP) has long term benefit as energy consumers are willing to adopt their consumption's behaviors and apply energy efficient products. However, a review of the existing researches on DR optimization suggests a need for further studies on the RTP, which is set by energy suppliers [10]. In particular, the contribution of flexible loads using RTP in maintaining the network constraints within permissible range is vital.

In the current GB electricity network, DNOs do not have full observability or real-time visibility of their networks. Therefore, DNOs may control and manage the network without fully understanding its topology. With a 
lack of system studies, it would be difficult to find the optimum locations of automatic supporting tools such as voltage regulators. Hence, the flexibility provision by DR does not limit on its benefit to constraint control but also enables other application such as fast frequency response, reserve capacity and etc.

From a power network's point of view, the contribution of residential flexible loads in network management can be investigated at both local and wide area levels. In the former, the DR control mechanism aims to control the local issues in LV networks such as transformer overloading and voltage constraints through individual consumer's available DR. On the other hand, wide area level studies, such as this one, refer to constraint management in Medium Voltage (MV) networks, e.g., voltage or current, through DR provided from aggregation of households in each LV feeder.

Under network stress condition, an immediate action is required to mitigate the constraints in the DN. Hence, from a technical perspective, incentive-based DR programmes [13] are the ones of interest because customers have contractual obligations for DR provision. However, at wide level, price-based DR programmes have also been considered [16]; additional network entities, such as aggregators and energy suppliers, are required [11] to provide DR from local level. However, the potentially available demand reduction is highly variable and dependent on consumer characteristics. Therefore, when implementing DR programmes, domestic users are generally considered as aggregate entities rather than individual ones [12] and this increases the overall system complexity. In [13], a model for studying the participation of a DR aggregator in wholesale markets has been proposed. The impact of considering multiple load aggregators has been investigated in [14] that indicated a great impact on shaving peak, decreasing energy loss, and reducing the operation cost.

In price-based DR approaches, the control mechanisms proposed in the literature have been based on defining and applying the network charges in the electricity price. A real time DR is presented in [15] for where the congestion management is controlled through adjustment of the electricity price by charging the cost of the transformer overloading. Similarly, Liu et al [16] proposed a distribution congestion price in a day-ahead market to relieve possible congestion in the DN [16]. An example of an effective alignment between the load and the grid real-time condition is the proposed scheme in [17] which adjusts aggregated thermostatic loads under real-time grid conditions. However, it can be observed that only a limited number of constraints have been considered in these studies. Moreover, the objectives of these DR control schemes are focused solely on either technical or economic aspects of DNs.

On the other hand, the implementation of DR from residential flexible resources in a wide-area network, necessitates a framework that incorporates various players with individual attributes. This can guarantee network reliability and security as well as meet all entities' objectives. Three types of frameworks have been developed: multi-layer [18], hierarchical [19], and Multi-Agent Systems (MAS) [20]. The first one consists of different layers where different entities exists in each layer having similar roles or attributes. Entities in each layer connect to all other agents in their upper layer. The hierarchical structure is similar to multi-layers but it consists of different levels where the entities in each level communicate with one entity in the upper level [21]. This structure is also known as supervisor-employee model. In the MAS, each network entity is modelled as an agent with specific behavior, attitudes and objectives [22]. Agents can communicate with each other in order to achieve their goals.

MAS, although a relatively new approach, is an established distributed control method [23] that has been applied in power systems. One of the significant advantages of MAS compare to other structures is that each agent (entity) can act independently. This improves the total system resilience and robustness as they are not affected by 
any local failure at component or communication pathway [24]. It has been found to provide a decentralized and intelligent framework to control and coordinate the network [23]. It can also minimize the computational burden of the central processor for optimizing the network and thus suitable for modelling a complex network.

A range of MASs has been applied to different types of DR programmes and several applications have included the participation of large-scale residential DR aggregators. The proposed MAS in [25] introduced a novel approaches to manage the distribution transformer overloading using incentive-based DR. Oliveira et al. proposed a MAS platform that can support several energy resource management models, as well as diverse DR programs [26]. However, these researches did not employed any market agent and thus the framework supports a limited range of DR scenarios and use of real data. A novel agent-based structure has been proposed in [27] which integrated the flexibility demand from both residential and industrial sectors. The optimization objective was the minimization of the total cost of energy, and regulation without considering the power network constraints. In [], authors used MAS to model multi micro grids in order to control the voltage in a fully decentralized way. The most recent studies in DR using MAS are reviewed in [28]. The major gaps in the literature for DR framework are the non-scalability [18, 29] or non-adoptable architecture [30], the limited application (e.g., limited number of studied constraints $[15,16]$, DR scenarios $[28,26,25])$ and the limited number of network entities, (e.g., market [26, 31] ).

The rationale behind this research is to provide an in-depth investigation of the potential responsiveness in residential demand and its effect on constraint management of the DN. Hence, the aim of this research is to implement a framework for DR automation using MAS in order to manage the voltage and thermal constraints under RTP. The novelty aspect of this paper is to provide a decentralized platform aiming to merge technical as well as economic benefits of enabling and controlling the DR in residential feeders. Therefore, DR trading can not only maximize social welfare of both end users and network operators/energy suppliers but also lessen MV/LV network violations from stipulated limits. The development of proposed MAS framework, if adopted by DNOs, can be an important tool to support the transition to the DSO model. The proposed framework is studied and validated under real-time environment and it represents a beneficial guideline for future network planning studies. Hence, the platform considered the future of DNOs where the term DSO is used in the proposed model as a replacement of DNOs. Furthermore, it can be used by aggregators or energy suppliers in order to investigate and model the behavior of the system and consumers.

The main contribution of this paper is the design and implementation of a new DR-MAS-based ADNM framework for voltage and current constraint management of MV feeders through available DR at LV feeders under real time environment with the following novel achievements:

1) A fast decision-making methodology for running residential controllable appliances.

2) A novel control strategy to determine the optimum magnitude and location of demand response.

3) Apply the proposed framework in a 69-bus test system with $8 \mathrm{MV}$ and $48 \mathrm{LV}$ feeders.

It is worth to clarify that in this paper only flexible demand from shiftable loads is considered. The overall network objectives are achieved by solving a power flow that is based on customer load profile characteristics, taking into account different personal (social, technical, educational and financial incentives) as well as external (time, day and seasonal) factors. The required flexible loads from each LV feeder is defined in half an hour basis.

The structure of the paper is as follows. The proposed MAS framework focusing on its cyber layer is described in section 2. The goals and attributes of each agent are modelled mathematically in section 3 . This is followed by a description of the overall DR algorithm. Section 5 explains the preparation and setting parameters for implementing 
the proposed framework. Section 6 presents the simulation results for two case studies followed by a discussion in the next section. Finally, concluding remarks and future work are provided in section 8 .

\section{Proposed Multi Agent System Framework}

This section describes the system model of the proposed MAS for residential DR scheme. The MAS implementation is based on an original approach that was described and developed in [32]. The general DR architecture model and data communication among agents is presented in Fig. 1. The framework consists of two different layers, physical and cyber layer. Components in the first layer and their corresponding agents in the second layer are modelled using MATLAB.

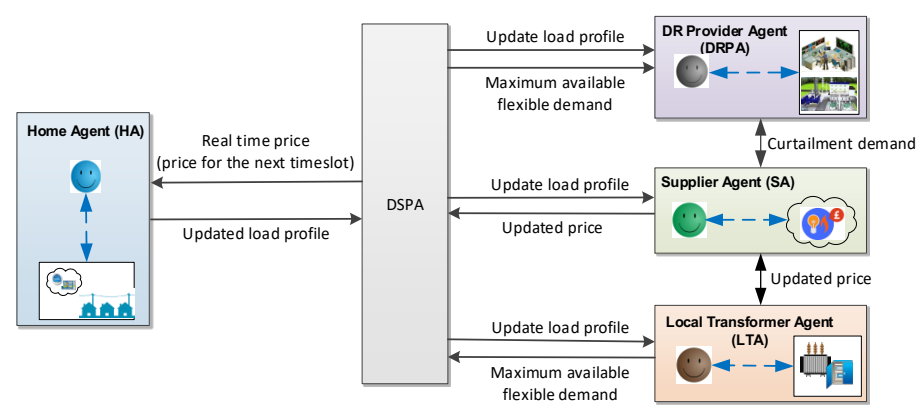

Fig. 1. Proposed MAS framework and overall scope of communications among agents: The solid line represents physical layer (power line) and the dashed line refers to cyber line (agents conceptual communication flows)

The proposed model provides a price-based energy management framework, consisting of dynamic sets of intelligent nodes, for aggregated domestic consumers. Specifically, the interest of this work is on studying the network under system stress conditions due to operational issues with the view to manage voltage and thermal constraints. In this regard, five kinds of agents are introduced as DR 2Provider Agent (DRPA), Supplier Agent (SA), Local Transformer Agent (LTA) and Home Agent (HA) and Data Service Provider Agent (DSPA).

DRPA represents the DSO that activates the DR in the network by implementing dynamic tariffs. These are set by electricity suppliers which are modelled by SA in the proposed MAS platform. HA and LTA represent household and LV feeder respectively. DSPA is added to the MAS framework to model the Data Communication Company (DCC) that interconnects smart meters to DSOs, suppliers and authorised service entities of the network in GB [33]. DSPA enables data exchange between the HAs and the LTAs, SA and DRPA. It should be noted that this paper assumed that the network comprises the same DSO and energy supplier. However, the MAS framework and DR algorithm can be modified to incorporate several DRPAs and SAs.

The system network comprises several lateral LV feeders which are controlled by a set of local distribution transformers LTA $=\{\mathrm{LTA} 1, \mathrm{LTA} 2, \ldots\}$ connecting to a set of households HA $=\{\mathrm{HA} 1, \mathrm{HA} 2, \ldots\}$. It is assumed that all HAs have smart meters and Home Energy Management Systems (HEMS) installed for DR performance. Another assumption is that communication between LTAs or SAs and HAs is done through DSPA. The timeframe for data update is split uniformly into 48 slots $\mathrm{T}=\{1, \ldots, 48\}$. The price of electricity is determined in real time 
(at each timeslot $t \epsilon T$ for the next half an hour $(t+1) \epsilon T$ ) by SA. In fact, SA acts as an electricity retailer who sets the tariffs and the incentives aiming towards DR fulfilment. The modelling details of each agents, their goals and behaviours are presented in section 3 and 4 .

\section{Mathematical Models}

\section{A. Home Agent}

The main aim of each HA is to decide about the start-up of each available appliance in real time, with the aim of minimising cost and maximising comfort level. Each individual household is considered as an autonomous agent which consists of a set of appliances $\mathrm{Ap}=\left\{\mathrm{ap}_{1, \ldots}, \mathrm{ap}_{\mathrm{n}}\right\}$. Home appliances are categorised as non-controllable and controllable, where the flexible loads are provided through the latter. Three major wet appliances that can be shifted during a typical day were considered and these were Washing Machine (WM), Dish Washer (DW) and Tumble Dryer (TD). The model of each controllable appliance is described in [34]. The total loads $\mathrm{l}_{\mathrm{t}, \mathrm{h}}$ at a given time $t$ can be defined as a set of aggregated loads as follows:

$$
\begin{gathered}
\mathrm{l}_{\mathrm{h}, \mathrm{t}}=\mathrm{l}_{\mathrm{h}, \mathrm{t}}^{\mathrm{ap}}=\mathrm{l}_{\mathrm{h}, \mathrm{t}}^{\mathrm{f}}+\sum_{\mathrm{w}}\left(\mathrm{l}_{\mathrm{h}, \mathrm{t}}^{\mathrm{sh}} * \mathrm{D}_{\mathrm{h}, \mathrm{t}}^{\mathrm{sh}}\right) \\
\forall \mathrm{h} \in \mathrm{H}, \mathrm{t} \in \mathrm{T},\left\{\mathrm{ap}, \mathrm{f}, \mathrm{sh}_{\}} \in \mathrm{AP}, \mathrm{D}_{\mathrm{h}, \mathrm{t}}^{\mathrm{sh}} \in[0,1]\right.
\end{gathered}
$$

Where,

$$
\mathrm{l}_{\mathrm{h}, \mathrm{t}}^{\mathrm{sh}}=\mathrm{l}_{\mathrm{h}, \mathrm{t}}^{\mathrm{WM}}+\mathrm{l}_{\mathrm{h}, \mathrm{t}}^{\mathrm{DW}}+\mathrm{l}_{\mathrm{h}, \mathrm{t}}^{\mathrm{TD}}
$$

Where $l_{h, t}^{s h}$ and $l_{h, t}^{f}$ are shiftable appliances and other loads of household $h$ at timeslot $t$ respectively. $l_{h, t}^{s h}$ comprises $l_{h, t}^{W M}, l_{h, t}^{D W}$ and $l_{h, t}^{T D}$ which represent consumption of WM, DW and TD correspondingly. The start-up of each appliance $s h$ is denoted by the binary variable $D_{h, t}^{s h}$ which is 1 for selected ones and 0 otherwise and is expressed as:

$$
\mathrm{D}_{\mathrm{h}, \mathrm{t}}^{\mathrm{sh}}=\left\{\begin{array}{l}
1, \forall \mathrm{d}_{\mathrm{h}, \mathrm{t}}^{\mathrm{sh}}>1 \\
0, \forall \mathrm{d}_{\mathrm{h}, \mathrm{t}}^{\text {sh }}<1
\end{array} \quad, \quad \forall \mathrm{h} \in \mathrm{H}, \mathrm{t} \in \mathrm{T}, \mathrm{sh} \in \mathrm{AP}\right.
$$

where,

$$
\mathrm{d}_{\mathrm{h}, \mathrm{t}}^{\mathrm{sh}}=\left(\mu_{\mathrm{h}, \mathrm{t}}^{\mathrm{sh}} \cdot \delta_{\mathrm{h}, \mathrm{t}}^{\mathrm{sh}}\right)+\lambda_{\mathrm{h}, \mathrm{t}}^{\mathrm{sh}}
$$

$d_{h, t}^{s h}$ denotes user-related constraints. $\mu_{h, t}^{s h}$ reflects the first goal of HA which is to verify the economic viability for starting up controllable appliances by considering the received price signal from SA. A value of 1 is allocated to $\mu_{h, t}$ for attractive prices. $\delta_{h, t}^{s h}$ relates to the satisfaction level of household and is 1 if the appliance $s h$ is selected. The binary variable $\lambda_{\mathrm{h}, \mathrm{t}}$ represents the ownership of appliance $s h$ at household $h$. The mathematical expressions for $\mu_{h, t}^{s h}$ is as follows:

$$
\mu_{h, t}^{s h}=\mathrm{A}_{\mathrm{h}, \mathrm{t}^{*}}^{\mathrm{sh}} \mathrm{E}_{\mathrm{h}, \mathrm{t}}^{\mathrm{sh}}
$$


$\mathrm{A}_{\mathrm{h}, \mathrm{t}}^{\mathrm{sh}}$ is the HA's willingness for DR participation and $\mathrm{E}_{\mathrm{h}, \mathrm{t}}^{\mathrm{sh}}$ reflects the price elasticity, expressed as:

$$
\mathrm{E}_{\mathrm{t}, \mathrm{h}}=\left\{\begin{array}{l}
1, \forall \mathrm{E}_{\mathrm{h}, \mathrm{t}}^{\mathrm{sh}} \geq \mathrm{I}_{\mathrm{h}, \mathrm{t}} \\
0, \forall \mathrm{E}_{\mathrm{h}, \mathrm{t}}^{\mathrm{sh}}<\mathrm{I}_{\mathrm{h}, \mathrm{t}}
\end{array}, \forall \mathrm{t} \in \mathrm{T}, \mathrm{h} \in \mathrm{H}\right.
$$

where,

$$
\mathrm{E}_{\mathrm{t}, \mathrm{h}}=\Delta \mathrm{C}_{\mathrm{h}, \mathrm{t}} \varepsilon_{\mathrm{c}, \mathrm{h}}+\mathrm{b}_{\mathrm{c}, \mathrm{h}}
$$

$\Delta \mathrm{C}_{\mathrm{h}, \mathrm{t}}$ is the price difference at timeslot t. $\varepsilon_{\mathrm{c}, \mathrm{h}}$ is the price elasticity of demand and $\mathrm{b}_{\mathrm{c}, \mathrm{h}}$ is a constant. $\mathrm{I}_{\mathrm{h}, \mathrm{t}}$ is the total demand including selected appliance.

In order to estimate the value of the parameters in (5-7), the approach in [35] was used. The methodology is centred on characteristic-based clustering of load profiles. These considerations include mean power usage as well as other individual and distinctive ones for each household. $A_{\mathrm{h}, \mathrm{t}}^{\mathrm{sh}}$ and $\varepsilon_{\mathrm{h}, \mathrm{c}}$ are determined for each cluster of households. $A_{\mathrm{h}, \mathrm{t}}^{\mathrm{sh}}$ is achieved through segmentation of customers according to their attitudes towards load curtailment programmes which resulted in three classifications, highly motivated, less motivated and doubter. $\delta_{\mathrm{h}, \mathrm{t}}^{\mathrm{sh}}$ relates to the set of constraints based on appliances availability, $\mathrm{k}_{\mathrm{h}, \mathrm{t}}^{\mathrm{sh}}$, and consumer preference, $\mathrm{w}_{\mathrm{h}, \mathrm{t}}^{\mathrm{sh}}$. These are expressed as:

$$
\begin{aligned}
& \delta_{\mathrm{h}, \mathrm{t}}^{\mathrm{sh}}=\left\{\begin{array}{l}
1, \forall\left(\mathrm{w}_{\mathrm{h}, \mathrm{t}}^{\mathrm{sh}} \cdot \mathrm{k}_{\mathrm{h}, \mathrm{t}}^{\mathrm{sh}}\right)=1 \\
0, \forall\left(\mathrm{w}_{\mathrm{h}, \mathrm{t}}^{\mathrm{sh}} \cdot \mathrm{k}_{\mathrm{h}, \mathrm{t}}^{\mathrm{sh}}\right)=0
\end{array}\right. \\
& \mathrm{w}_{\mathrm{h}, \mathrm{t}}^{\mathrm{sh}}=\left\{\begin{array}{l}
1, \forall \mathrm{t} \in \Delta \mathrm{t}_{\mathrm{h}, \mathrm{t}}^{\mathrm{sh}} \\
0, \forall \mathrm{t} \notin \Delta \mathrm{t}_{\mathrm{h}, \mathrm{t}}^{\mathrm{shref}}
\end{array},\right. \\
& \mathrm{k}_{\mathrm{h}, \mathrm{t}}^{\mathrm{sh}}=\left\{\begin{array}{l}
1, \forall\left(\mathrm{x}_{\mathrm{h}, \mathrm{t}}^{\mathrm{sh}} \cdot \mathrm{z}_{\mathrm{h}, \mathrm{t}}^{\mathrm{sh}}\right)=1 \\
0, \forall\left(\left(\mathrm{x}_{\mathrm{h}, \mathrm{t}}^{\mathrm{sh}} \cdot \mathrm{z}_{\mathrm{h}, \mathrm{t}}^{\mathrm{sh}}\right)=0\right.
\end{array}\right.
\end{aligned}
$$

$\Delta \mathrm{t}_{\mathrm{h}, \mathrm{t}}^{\text {sh,pref }}$ for operating an appliance $\mathrm{sh} \in \mathrm{AP}$ depends on the starting time to operate an appliance $\mathrm{t}_{\mathrm{st}, \mathrm{h}}^{\mathrm{sh}}$ and its cycle length:

$$
\Delta \mathrm{t}_{\mathrm{h}, \mathrm{t}}^{\mathrm{sh}, \mathrm{pref}}=\rho_{\mathrm{h}, \mathrm{t}}^{\mathrm{sh}} \cdot \mathrm{k}_{\mathrm{h}, \mathrm{t}}^{\mathrm{sh}}
$$

Using the methodology introduced in [34], the probability of using an appliance $s h$, at a timeslot $t$ was estimated as a variable $\rho_{h, t}^{s h}$ for different clusters of households, similar to the approach presented in [34]. The proposed methodology has considered the appliance ownership, frequency usage, household characteristics as well as technical aspects of operating an appliance, such as energy constraints, in predicting the $\rho_{h, t}^{s h}$ within each cluster. Energy constraints ensure that the required energy for completing the operating cycle of appliance $s h$ is provided. 
Although an appliance may operate in multiple but interruptible cycles, this paper considers that all wet appliances should be operating continuously from the start until the end of their operating time. This is modelled by the binary variable $x_{h, t}^{s h}$. Moreover, the frequency of usage per appliance is assumed to be one and is presented by binary variable $z_{h, t}^{s h}$. This variable also considered the assumption that only one appliance $s h$ can run at any given time.

\section{B. Local Transformer Agent}

The role of each LTA is limited to sending the information regarding the available flexible loads from the associated HAs to DRPA through DSPA. Using the approach in [34], the available flexible demand from HAs over time is estimated. Since one operating appliance $s h$ is considered at each given timeslot, the probability of maximum shiftable appliances from each HA is averaged. Then, the maximum DR potential of each LTA is computed by summing all aggregated DRs from the related HAs.

\section{DR Provider Agent}

The power network could experience critical conditions due to overloading issues at distribution feeders. Therefore, the network constraints should be kept within the allowable boundary. In this respect, a multi-objective function is defined for DRPA aiming to manage the constraints in the DN using available DR sources This is expressed as equation (12) which consists of three sub-objectives including, $\sum^{L B, t} \frac{\Delta P_{l v, t}^{D R}}{S I_{\max , l v}}, \quad V D I_{t}$ and $\left.R P L I_{t}\right)$ where the contribution of each is determined using weighting factors. The explanation of each term is detailed in the following.

$$
\begin{gathered}
\operatorname{Min}\left(f=w_{1} \sum_{l v, t}^{L B, T} \frac{\Delta P_{l v, t}^{D R}}{S I_{\text {max }, l v}}+w_{2} V D I_{t}+w_{3} R P L I_{t}\right) \\
, \forall l v \in L V, t \in T
\end{gathered}
$$

Subject to the following constraints:

$$
\begin{gathered}
P_{n, t}^{D}=P_{n, t}^{G}+P_{n, t}^{L} \\
Q_{n, t}^{D}=Q_{n, t}^{G}+Q_{n, t}^{L} \\
V_{\min } \leq V_{n, t} \leq V_{\max } \\
S_{b r, t} \leq S_{\max } \\
\Delta P_{\text {min }, l v, t} \leq \Delta P_{l v, t}^{D R} \leq \Delta P_{\max , l v, t}
\end{gathered}
$$

where $w_{1}, w_{2}$ and $w_{3}$ are weighting factors with the total sum of one as shown in (18).

$$
\sum_{i=1}^{3} w_{i}=1, \quad \forall 0 \leq w_{i} \leq 1
$$

It is worth to note that the same values are selected for all weighting factor $\left(w_{1}=w_{2}=w_{3}=1 / 3\right)$ in order to employ the same contribution effect of each objective terms on the main objective function. However, the selection of these weighting factors depends on the user application and the purpose of DR implementation and can be varied to highlight the most prominent and relevant factors. 
The first sub-objective $\left(w_{1} \sum l v, t \frac{\Delta P_{l v, t}^{D R}}{S I_{\max , l v}}\right)$ refers to the optimal location and quantity of load reduction in each LV feeder. $\sum l v, t=P_{l v, t}^{D R}$ is the total required DR and $S I_{\max , l v}$ is the highest voltage sensitivity index from all the buses in that feeder. The approach in [36] was used to calculate the voltage sensitivity in order to determine the most influential buses in the network for demand reduction. The proposed method is dependent on the topology of the network and the sensitivity coefficients are defined as:

$$
\frac{\partial V_{m}}{\partial Q_{n}}=-R_{m-1, n-1}
$$

where, the voltage sensitivity is a matrix of $(\mathrm{m} \times \mathrm{n})$ presenting the voltage sensitivity of bus $m$ in respect to the active power variation at bus $n$. Since the voltage at bus slack is always constant $\frac{\partial \mathrm{V}_{1}}{\partial \mathrm{Q}_{\mathrm{n}}}=0$.

The second sub-objective $\left(w_{2} V D I_{t}\right)$ aims to minimise the Voltage Deviation Index (VDI) which is defined as the sum of the voltage differences at all buses (excluding the one at the substation where voltage is known) with respect to the nominal value. This is mathematically expressed as:

$$
\begin{gathered}
\text { VDI }=\frac{\sum \mathrm{n}, \mathrm{t}\left(\mathrm{V}_{\mathrm{nom}}-V_{\mathrm{min}, \mathrm{n}, \mathrm{t}}^{\mathrm{DR}}\right)^{2}+\left(\mathrm{V}_{\mathrm{nom}}-\mathrm{V}_{\mathrm{max}, \mathrm{n}, \mathrm{t}}^{\mathrm{DR}}\right)^{2}}{\sum \mathrm{n}, \mathrm{t}\left(\mathrm{V}_{\mathrm{nom}}-\mathrm{V}_{\mathrm{min}}\right)^{2}+\left(\mathrm{V}_{\mathrm{nom}}-\mathrm{V}_{\max }\right)^{2}}, \\
\forall \mathrm{n} \in \mathrm{NB}, \mathrm{n} \neq 1, \mathrm{t} \in \mathrm{T}
\end{gathered}
$$

where $V_{\min , n, t}^{D R}$ is the minimum voltage and $V_{\max , n, t}^{D R}$ is the maximum voltage of node $n$ with DR control at timeslot $t$ respectively. $V_{\text {nom }}, V_{\min }$ and $V_{\max }$ are assumed to be $1,0.94$ and 1.1 respectively as per UK standards.

The last sub-objective $\left(w_{3} R P L I_{t}\right)$ minimises the Real Power Loss Index (RPLI) which is formulated as:

$$
R P L I=\frac{P_{10 s s, t}^{D R}}{P_{\text {loss, }}^{W D R}}, \quad \forall t \in T
$$

Where, $P_{\text {loss, },}^{W D R}$ and $P_{\text {loss }, t}^{D R}$ denote the total real power loss before and after implementing DR at timeslot $t$. and Total power loss is expressed as

$$
\begin{gathered}
P_{t}^{L}(n, n+1)=\sum_{n, t} R_{n, n+1}\left[\frac{\left.V_{n, t}-V_{n+1, t}\right]}{Z_{n+1, t}}\right]^{2}, \\
\forall n \in N B, n \neq 1, t \in T
\end{gathered}
$$

Where $R_{n, n+1}$ is the resistance, $V_{n, t}$ and $V_{n+1, t}$ are the voltages and $Y_{n+1, t}$ is the impedance between two consecutive buses ( $n$ and $n+1$ ).

AC power flow equations are considered in (13-14) and are solved using the backward-forward sweep method [37]. Active power demand, generation and loss at node $n$ at timeslot $t$ are denoted as $P_{n, t}^{D},, P_{n, t}^{G}$ and $P_{n, t}^{L}$ respectively while reactive power demand, generation and loss are represented by $Q_{n, t}^{D}, Q_{n, t}^{G}$ and $Q_{n, t}^{L}$. Equation (15) gives the voltage limits in the DN which are $\pm 6 \%$ in this paper. Equation (16) is the thermal limit of branch $b r$, where $S_{b r, t}$ is determined from (23-25).

$$
S_{b r, t}=\sqrt{P_{b r, t}^{2}+Q_{b r, t}^{2}}
$$




$$
\begin{gathered}
\mathrm{P}_{\mathrm{br}, \mathrm{t}}=\sum_{\mathrm{n}, \mathrm{t}}^{\mathrm{BR}(\mathrm{br}, 1), \mathrm{T}} \mathrm{P}_{\mathrm{n}, \mathrm{t}}^{\mathrm{G}}+\sum_{\mathrm{n}}^{\mathrm{BR}(\mathrm{br}, 2), \mathrm{T}} \mathrm{P}_{\mathrm{n}, \mathrm{t}}^{\mathrm{L}} \\
\mathrm{Q}_{\mathrm{br}, \mathrm{t}}=\sum_{\mathrm{n}, \mathrm{t}}^{\mathrm{BR}(\mathrm{br}, 1), \mathrm{T}} \mathrm{Q}_{\mathrm{n}, \mathrm{t}}^{\mathrm{G}}+\sum_{\mathrm{n}, \mathrm{t}}^{\mathrm{BR}(\mathrm{br}, 2), \mathrm{T}} \mathrm{Q}_{\mathrm{n}, \mathrm{t}}^{\mathrm{L}} \\
, \forall \mathrm{br} \in\left\{\mathrm{BR}, \mathrm{br}^{\prime}\right\}, t \in \mathrm{T}, \mathrm{n} \in \mathrm{NB}
\end{gathered}
$$

where $S_{b r, t}, P_{b r, t}$ and $Q_{b r, t}$ are apparent, active and reactive power flow in branch $b r$, and $P_{n, t}^{G}, Q_{n, t}^{G}, P_{n, t}^{L}$ and $Q_{n, t}^{L}$ are the active power, reactive power, active power loss and reactive power loss fed by $b r$ respectively. The number of nodes fed by branch $b r$ is denoted by $b r^{\prime}$.

$\Delta P_{l v, t}^{D R}$ in equation (17) expresses the available DR at each LV feeder, determined by TRA, and is constrained within the minimum $\left(\Delta P_{\min , l v, t}\right)$ and maximum $\left(\Delta P_{\max , l v, t}\right)$ DR availability.

A Genetic Algorithm (GA) implemented by the global optimization toolbox in MATLAB, as illustrated in Fig. 2 , was used to solve the objective function (12). A penalty strategy was used to create the fitness function where the violation of constraints (15-17) are modelled as penalty term.

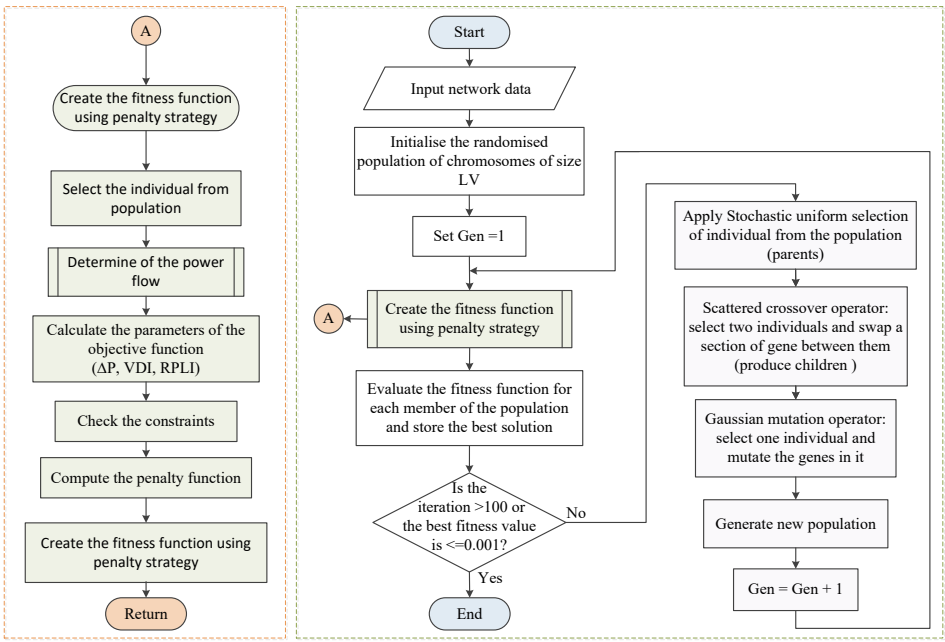

Fig. 2. Flowchart implementing the Genetic Algorithm to solve the objective function (12).

\section{Supplier Agent}

The SA is responsible for designing electricity tariffs and biding for HAs. Aiming to have a more effective, dynamic and active network, this paper suggests the price to be updated for each LV feeder individually. The rationale behind this was to present different attributes of consumers in demand reduction as in reality each consumer can chose different supplier with different pricing rates. This actually models having different suppliers and therefore customer characteristics across the network and is this policy is applied for simplifying the simulating the proposed framework. Therefore, for each LV feeder, the electricity payment linearly increases with the amount of energy to be reduced/shifted. Accordingly, a two-level piecewise linear pricing function $P_{l v, t}$ is used to define the half-an hour basis price and is expressed as: 


$$
\mathrm{P}_{\mathrm{lv}, \mathrm{t}}=\left\{\begin{array}{cr}
\propto_{1} P R_{l v, t}^{D R}+\beta_{1}, & \forall P R_{l v, t}^{D R} \leq 70 \% \\
\propto_{2} P R_{l v, t}^{D R}+\beta_{2}, & \forall P R_{l v, t}^{D R}>70 \% \\
\forall \propto_{1}<\propto_{2}, \mathrm{lv} \in \mathrm{LV}, \mathrm{t} \in \mathrm{T}
\end{array}\right.
$$

where,

$$
P R_{l v, t}^{D R}=\frac{\Delta \mathrm{P}_{\mathrm{lv}, \mathrm{t}}^{\mathrm{DR}}}{\Delta \mathrm{P}_{\mathrm{lv}, \mathrm{t}}} * 100
$$

$\mathrm{PR}_{\mathrm{lv}, \mathrm{t}}^{\mathrm{DR}}$ is the participation rate, $\Delta \mathrm{P}_{\mathrm{v}, \mathrm{t}}^{\mathrm{DR}}$ is required $\mathrm{DR}$ and $\Delta \mathrm{P}_{\mathrm{lv}, \mathrm{t}}$ is the available one. $\beta_{1}$ and $\beta_{2}$ are constants based on the fixed prices. $\alpha_{1}$ is the slope of the first segment is the step 1. Once the energy exceeds the threshold, the slope becomes $\alpha_{2}$ (Fig. 3). The coefficients in (26) are obtained by using the price data introduced in the project in [38]. This pilot was implemented as the first dynamic Time of Use (ToU) tariffs in GB in order to investigate the potential of dynamic pricing to provide residential DR. These price bands were determined by EDF Energy supplier [39] as High: 67.2 pence/kWh, Default: 11.76 pence/kWh and Low: 3.99 pence/kWh.

The proposed RTP provides the opportunity to use the residential DR for DSOs, where they can contribute to the network constraint management. In addition, the price allocated for each LV feeder, Fig. 3, is set and updated in real time taking in to account the available and required flexible loads, as well as the attitudes of users to demand reduction within that feeder.

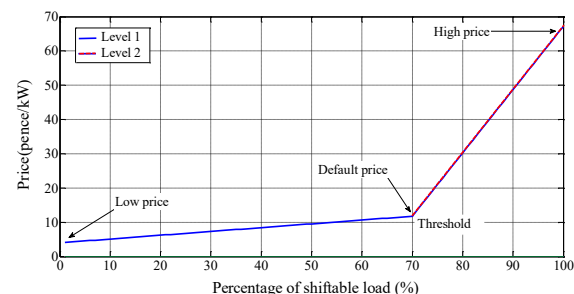

Fig. 3. Proposed pricing function in (26)

\section{E. Data Service Provider Agent}

DSPA enables data communications among different agents in the network. As the meter reading is recorded in half hourly resolution during a typical day, 48 samples are produced during interval $\mathrm{T}=\left\{\mathrm{t}_{1}, . ., \mathrm{t}_{48}\right\}$. Each agent sends updates through DSPA in each time interval. However, in each timeslot $t$, the HAs are informed about the price of electricity for only the next half hour $t+1$.

\section{Overall Proposed DR Algorithm}

This section describes the overall approach in order to implement the price-based DR in real time. The proposed algorithm is presented in Fig. 4. Each colour represents a particular agent undertaking a specific process as illustrated in Fig.1. Each sub-process is explained in related subsection of section 3. At each timeslot $t$, agents update their data. Then DRPA determines the network status to detect any constraint violation by running a power flow and accordingly computing network parameters such as voltage and power in buses. If any violation is detected, the optimal flexible loads e for each LV feeder $\left.\left(\Delta \mathrm{P}_{\mathrm{lv}, \mathrm{t}}^{\mathrm{DR}}\right)\right)$ is calculated for implementation in the next 
time slot $t$-1. Afterwards, SA specifies the real time price using (25-26). Accordingly, HAs decide about starting up any available controllable appliances and update their load profiles. LTA then calculates the available flexible loads for the next timeslot. It is worth to clarify that MV network constraints management is only undertaken through active power at each bus. It is assumed that the overloading of each MV/LV transformer is controlled locally by the LTA.

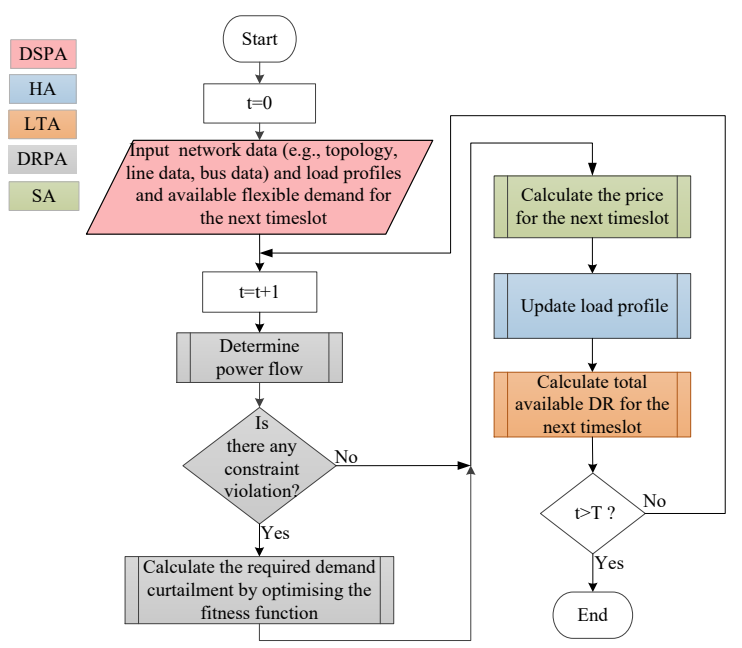

Fig. 4. Overall algorithm of the proposed active network management through DR in real time.

The actual total demand reduction $D R_{t}^{\text {actual }}$ in each LV feeder can be defined as:

$$
D R_{t}^{\text {actual }}=\sum l v\left(\mathrm{l}_{\mathrm{lv}, \mathrm{t}}^{\mathrm{DR}}-\mathrm{l}_{\mathrm{lv}, \mathrm{t}}\right), \quad \forall \mathrm{lv} \in \mathrm{LV}, \mathrm{t} \in \mathrm{T}
$$

where $l_{l v, t}$ and $l_{l v, t}^{D R}$ are the load profiles before and the after DR at timeslot $t$ of $l v^{\text {th }}$ feeder respectively.

\section{Simulation Modelling and Setup}

To validate the proposed MAS, a modified IEEE 69-bus $12.66 \mathrm{kV}$ radial DN is utilised as the test system which comprises $8 \mathrm{MV}$ and $48 \mathrm{LV}$ feeders as shown in Fig. 5. Each LV feeder is fed from a $12.6 / 0.415 \mathrm{kV}, 45 \mathrm{kVA}$ MV/LV transformer. The line and transformer parameters are available in [40, 41].

Each LV feeder consists of 19 nodes, representing two households each which results in a total of 1824 households in the test network. In order to specify the load profile for each HA, the dataset of the Ireland Electricity Smart Metering Trials (IEMST) [42] which consists of 4232 Irish households with half hourly meter readings was used. In this study, the data related to a summer month, July, and only for weekdays is considered. In addition, customers with meter readings missing for more than one day were removed and this resulted in a total of 3996 customers. 


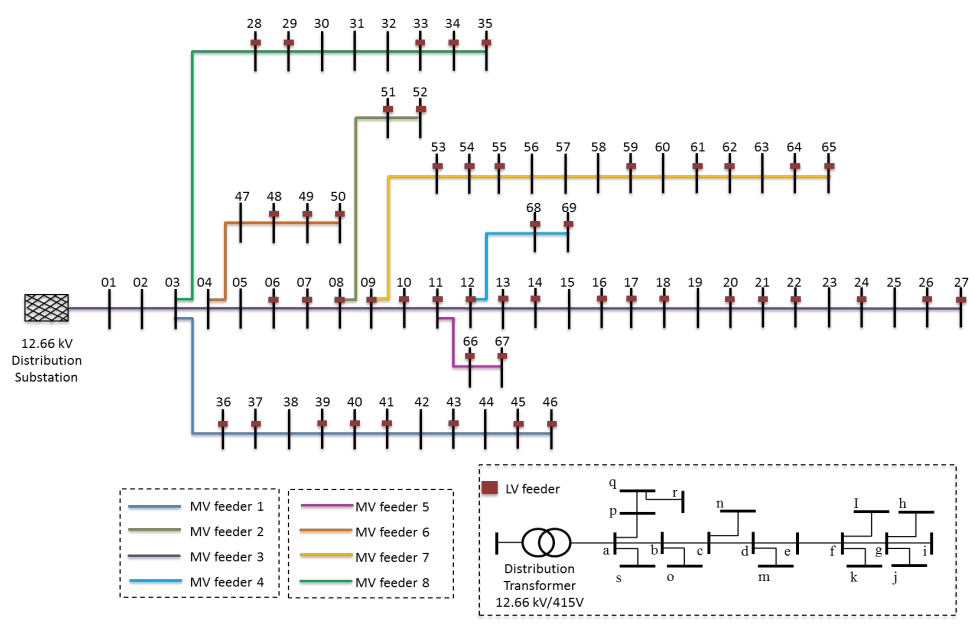

Fig. 5. One line diagram of the test system consisting of $8 \mathrm{MV}$ and $48 \mathrm{LV}$ feeders

The load profiles are clustered using the Dirichlet Process Mixture Model (DPMM) [43]. The DPMM is a Bayesian non-parametric statistical model that integrates Dirichlet and Multinomial distributions hierarchically. Load profiles are represented as draws from the latter. The advantage of the model is that the number of clusters does not need to be determined before clustering. The iteration results in a partition with six clusters (see Fig. 7). According to the clustering results, 1824 synthetic load profiles were generated to present the variability among consumers consumption behaviour. For each cluster, the load profiles were created randomly around its centroid, based on normal distribution. The results of synthetic data generated from clustering results are shown in Fig. 6. The simulation period is one day with 48 timeslots, half an hour resolution. Timeslot $\mathrm{t}=1$ represents 00:00:0000:23:59 hrs.
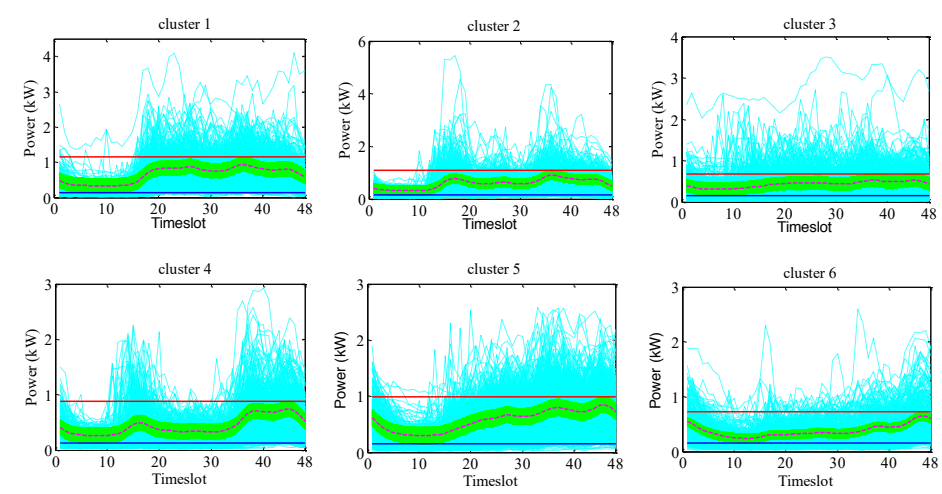

- Minimum profile within the cluster - Historical load profiles

Fig. 6. 1824 synthetic load profiles of HAs created from resulting 6 cluster 
The spread of households along with their attitudes towards DR participation is depicted in Fig. 7. In addition, the assumption for coefficients (6) used to assess the elasticity of each cluster of customers in the simulating models, are summarised in Table I.

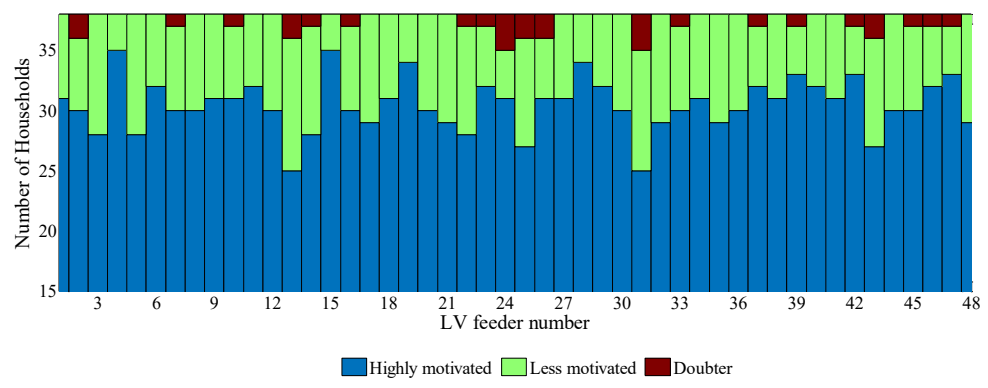

Fig. 7. Distribution of households and their readiness to participate in DR programmes

Table I. Setting coefficients of parameters $\boldsymbol{\varepsilon}_{\mathbf{c}}$ and $\boldsymbol{b}_{\boldsymbol{c}}(6)$

\begin{tabular}{|c|c|c|}
\hline Cluster No & $\varepsilon_{c}$ & $b_{c}$ \\
\hline 1 & 0.5485 & -0.4009 \\
\hline 2 & 0.807 & -0.2799 \\
\hline 3 & 0.556 & -0.1926 \\
\hline 4 & 0.6759 & -0.2342 \\
\hline 5 & 0.4294 & -0.1488 \\
\hline 6 & 0.39 & -0.1072 \\
\hline
\end{tabular}

\section{Simulation Results}

The simulation outputs for two scenarios are provided in this section. The result without load control is taken as the reference while the one with RTP is the proposed model. The modelling and simulation are undertaken separately for both cases with a view to compare the results and analyse the effectiveness of the proposed model.

Scenario \#1) Without Load Control: In this scenario, DR is not applied in the network. Therefore the results are obtained by distributing the load profiles across the test network, running the power flow and determining the network status during simulation. The price for all HAs are the same. This is the reference scenario referred in this research as WDR.

Scenario \#2) With RTP: This is the proposed model with real time prices being sent to HAs. The dynamic change in the pricing is based on the network status as well as the aggregated household demand. The prices are different for each LV feeder but are fixed for all households within that feeder. Although the initial load profiles are the same as the first scenario, they change after households individually decide on the start of their shiftable appliances. This scenario is named DR in this research.

It is worth to note that in scenario \#1, for each appliance $s h$ in each household $h$, the default of start time, $t_{h, t}^{s h}$, is considered as a random selection among $\Delta t_{h, t}^{\text {sh,pref }}(11)$. Accordingly, in scenario $\# 2$, this time is updated based on the proposed model for HAs' decision-making on the start of the appliances. Moreover, as mentioned in section 3 , the weighting factors of the objective function (12) in scenario \#2 are assumed to be equal. 
The output of the simulation for determining the pricing in the proposed methodology together with the aggregated load profiles of HAs is presented in Fig 8. The spread of the RTP for each timeslot in all the feeders is shown in Fig. 8(a) while the total demand for both scenarios is illustrated in Fig.8 (b). The price is separately allocated to each LV feeder according to network status and their DR potential.
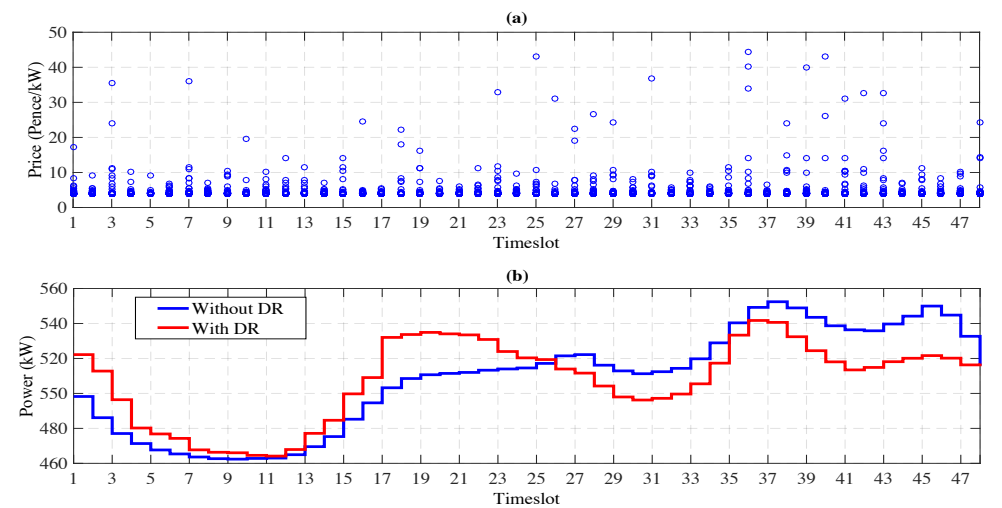

Fig. 8. Pricing for the proposed RTP scheme in scenario \#2 (a) and total aggregated load profiles all HAs in the network from both scenarios (b).

The total percentage of change in power at each LV feeder after DR implementation is shown in Fig. 9 for a one-day simulation period. As can be seen, the evening peak demand is shifted to morning non-peak times. No considerable change is observed in the Peak-to-Average Power Ratio (PAPR), which aims to flatten the overall demand over time. This can be explained by the fact that PAPR has not been considered in the objective function of DRPA since the aim of the proposed framework is to mitigate the DN constraints through DR. The standard deviation is decreased to $25 \%$ when DR is applied.

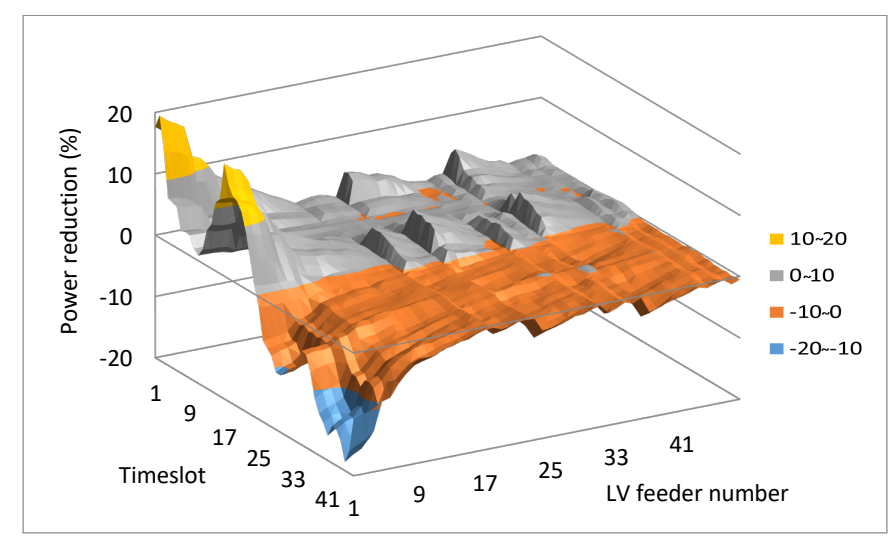

Fig. 9. Demand reduction along LV feeders 
Fig. 10 uses boxplots to illustrate the voltage magnitude distribution of LV buses connected to each MV feeder for both scenarios in 48 timeslots. In scenario \#2, the voltages at MV connection points are improved and maintained within the allowable boundary. This is also verified in Fig. 11 which shows the minimum voltage among all buses in the network for both scenarios. In spite of voltage reduction at some timeslots, e.g., 17-21, the voltage level was kept within statutory limit. For both scenarios, the VDI drawn in Fig. 12 illustrates that the voltage deviation from the reference point is reduced in all buses. This confirms the validity and effectiveness of considering VDI minimisation in the DRPA objective function.

(a)

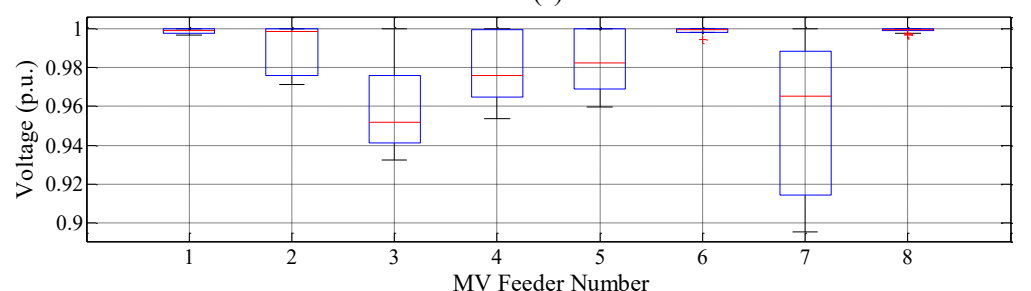

(b)

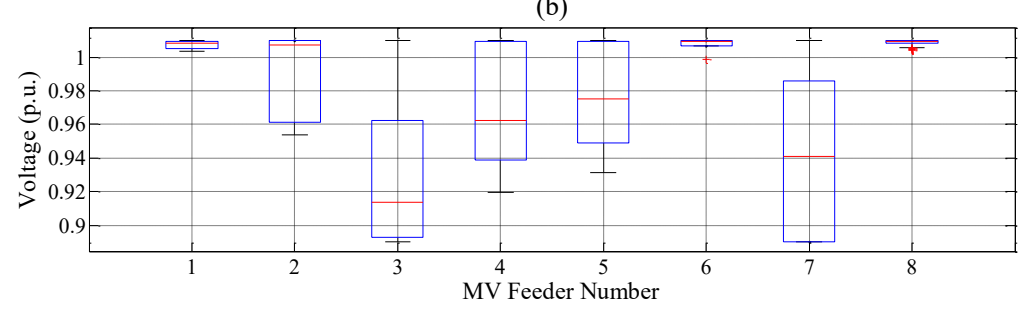

Fig. 10. Voltage distribution at the MV connection points in scenario \#1 (a) and scenario \#2 (b)

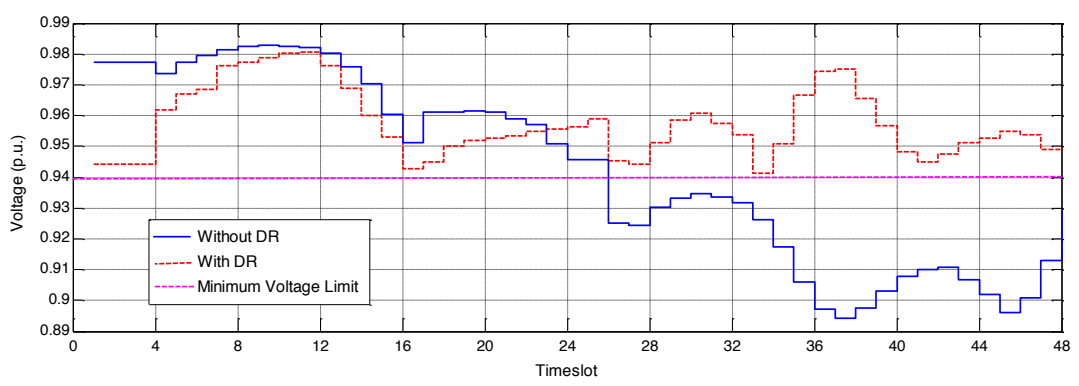

Fig. 11. Minimum voltage profile of the test network for both scenarios during simulation 


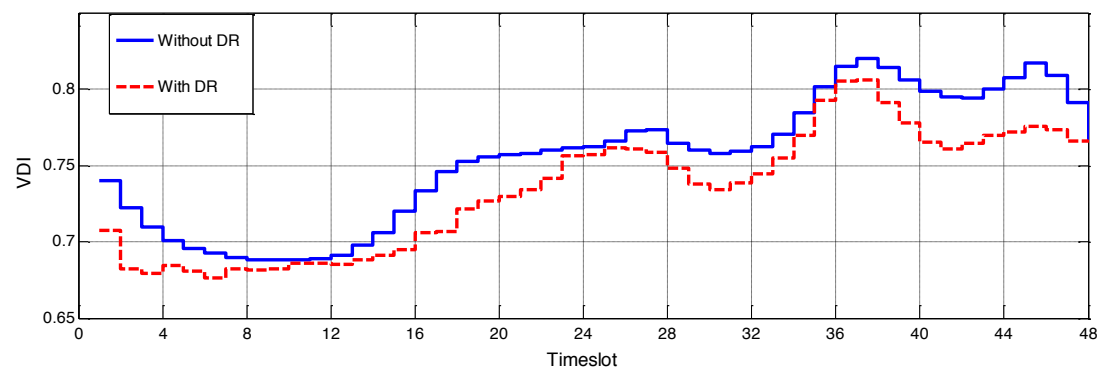

Fig. 12. VDI before and after DR

Fig. 13 presents the total power loss during the simulation period. As can be observed, there is a marginal increase in power loss in scenario \#2 at some timeslots and this could be attributed to peak load aggregation. However the overall system power loss decreased by $0.28 \mathrm{kWh}$. Additionally, it can be seen from Fig. 14 that after implementing DR there is a dip in RPLI in timeslots $25-48$ due to a reduction in total demand. Furthermore, no significant increase was noted for periods with rises in overall load.

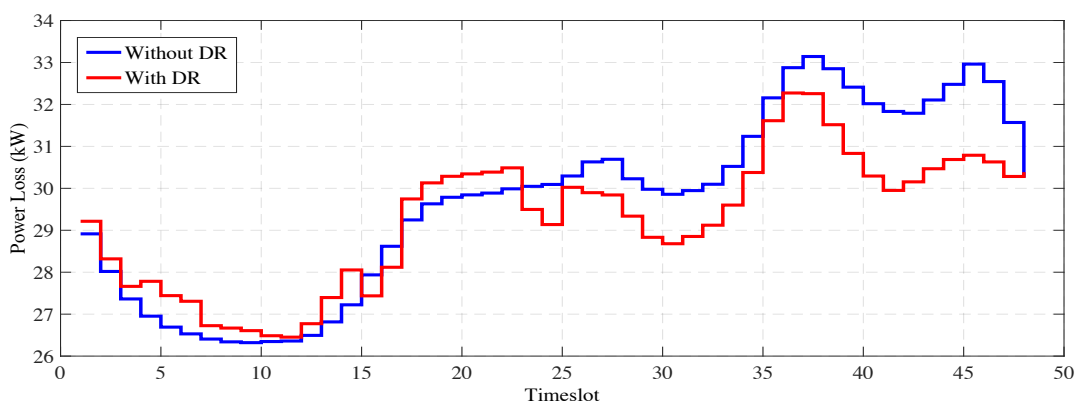

Fig. 13. Total power loss in the network for both scenarios during simulation

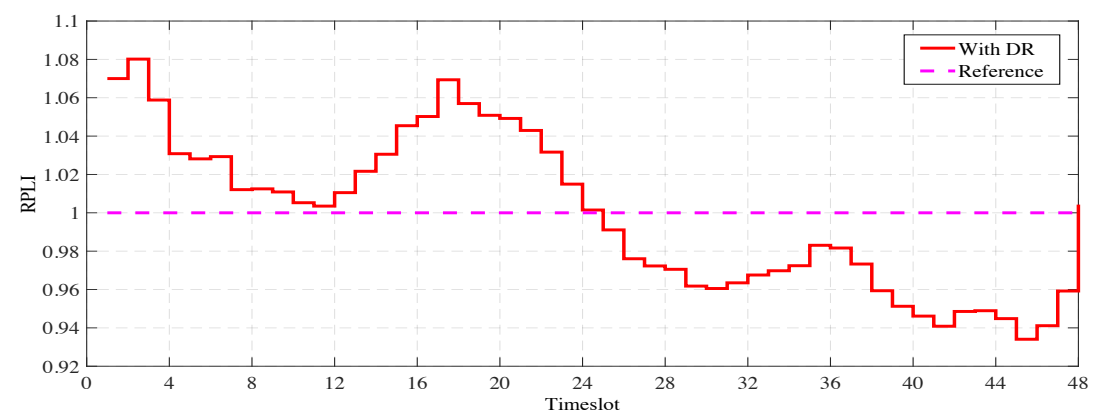

Fig. 14. RPLI after implementing the proposed DR mechanism 


\section{Discussion}

This section comprises a thorough analysis of the results as well as the various characteristics of the proposed MAS strategy.

\section{A. Effect of Pricing on Power Reduction}

In order perform a comprehensive analysis of the computation technique employed for implementing RTP tariffs in the proposed scheme, the worst case scenario is used. This was achieved by selecting the feeder with the most critical voltage level in the network, MV feeder 7, as depicted in figure 11(a). As illustrated in the resulting voltage profile along the feeder in Fig. 16, the voltage is not only improved but it is also kept within the tolerable boundary. The lowest voltage level prior to applying DR was at timeslot 37 and this was chosen for this investigation. The voltage profile for this timeslot is shown in Fig. 17 for all buses within the feeder. It was noted that the further the buses were from the feeder, the lower voltages they experienced. Furthermore, since the voltage levels of the last nine buses were under the acceptable limit without DR, it becomes necessary to implement a DR control strategy to raise the voltage to be within the allowable boundary. The buses with the maximum voltage sensitivity are the most optimum location for load curtailment. However due to several constraints in the objective function such as the available DR limit in each LV feeder, the maximum required DR is not always assigned to those buses. As an example, in this work, feeder 59 has the highest power reduction. However the highest voltage sensitivity are for buses 61-65. The maximum price is allocated to feeder 62 which has the highest participation rate.

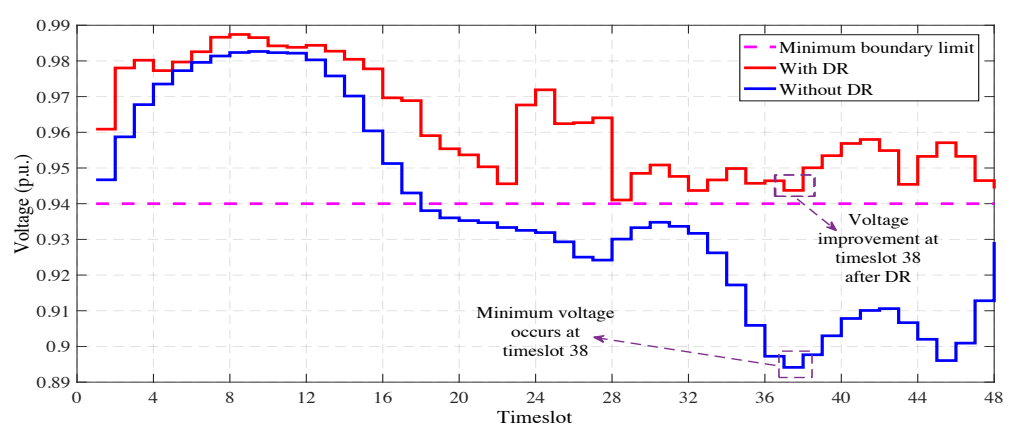

Fig. 16. Voltage profile for MV feeder 7

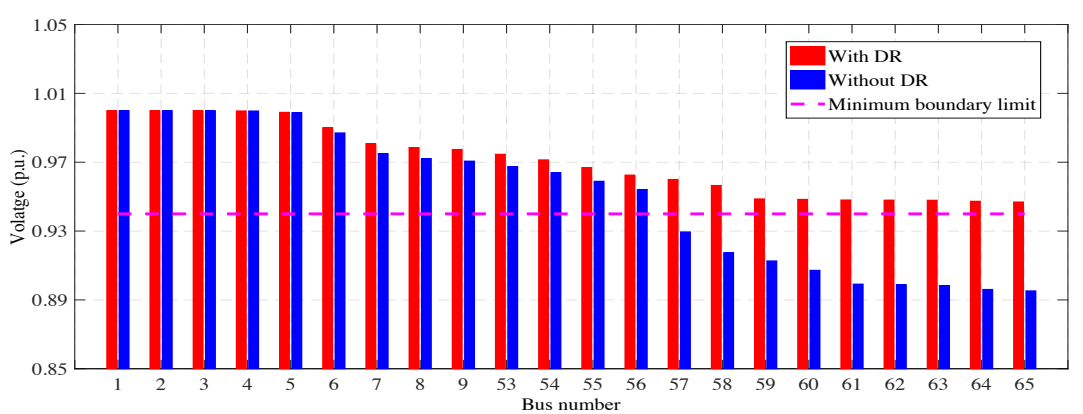


Fig. 17. Voltage profile for individual buses in MV feeder 7 at timeslot 37

The calculated values for the parameters needed to apply the proposed DR control are given in Table II. The only buses shown are those connected to LV feeders (12 buses). The total available flexible load was $21.312 \mathrm{~kW}$ while the $14.80 \mathrm{~kW}$ required one was computed from (12). Based on $P R_{l v, t}^{D R}(26)$, the individual price for each $\mathrm{LV}$ feeder was determined. After applying the proposed methodology, the resultant overall demand reduction was $14.77 \mathrm{~kW}$. The accuracy in the result is an indication of the feasibility and effectiveness of this DR mechanism. It is worth noting that due to the assumption of constant power factor for all loads, a proportional amount of reactive power is also reduced along with the real power.

Table II. Calculated parameter for applying DR at MV feeder 7 at timeslot 37.

\begin{tabular}{c|cccccc}
$\begin{array}{c}\text { Bus No. } \\
\text { (LV feeder) }\end{array}$ & Sensitivity & $\begin{array}{c}\text { Available DR } \\
(\mathrm{kW})\end{array}$ & $\begin{array}{c}\text { Required DR } \\
(\mathrm{kW})\end{array}$ & $\begin{array}{c}\left(\Delta \mathrm{P}_{\mathrm{lv}, \mathrm{t}}^{\mathrm{DR}}\right) \\
(\%)\end{array}$ & $\begin{array}{c}\text { Actual DR } \\
(\mathrm{kW})\end{array}$ & $\begin{array}{c}\text { Price } \\
(\text { Pence/kWh })\end{array}$ \\
\hline 6 & 0.0018 & 0.03 & 0 & 8.11 & 0.019 & 4.89 \\
7 & 0.0020 & 0.19 & 0.09 & 46.27 & 0.05 & 9.13 \\
8 & 0.0021 & 2.38 & 0.748 & 31.38 & 1.03 & 7.47 \\
9 & 0.0031 & 1.96 & 0.871 & 44.33 & 1.16 & 8.91 \\
53 & 0.0024 & 3.48 & 2.765 & 79.43 & 2.043 & 29.19 \\
54 & 0.0025 & 4.36 & 3.596 & 82.46 & 3.26 & 34.78 \\
55 & 0.0027 & 0.97 & 0.717 & 74.06 & 0.953 & 12.21 \\
59 & 0.0041 & 0.51 & 0.379 & 74.96 & 0.198 & 20.92 \\
61 & 0.0043 & 2.02 & 0.634 & 31.33 & 0.688 & 15.24 \\
62 & 0.0043 & 1.86 & 1.63 & 87.70 & 1.79 & 44.47 \\
64 & 0.0045 & 1.14 & 0.94 & 82.10 & 1.07 & 34.12 \\
65 & 0.0056 & 2.68 & 2.291 & 85.38 & 2.539 & 40.18 \\
\hline
\end{tabular}

\section{B. Scalability of the Proposed Framework}

The implementation of the MAS framework demonstrated the interaction between the different players in communicating, collaborating and negotiating with each other can achieve the system goal. The proposed DR approach can provide an environment where the overall target of the system is split into sub-tasks and distributed among agents and thus the minimising the computational process. The responsibility of DSO is focussed into monitoring the network status and determining the optimum amount and location of DR implementation. Forecasting the price elasticity of demand or quantity of available flexible load are not the DSO's remit. LTAs which are the DR aggregators, have the task of providing the available flexible loads from their associated HAs. The SA has to set the price for each LV feeder. As a result, the proposed MAS framework eases the communication among agents and simplifies the analytical processing.

The number of households or the incorporation of new loads or generations does not have a considerable effect on the complexity or processing time and of the DR mechanism. This can be attributed to the following reasons:

1) The input data at DSO or SO level, such as quantity of available flexible load or required demand, are provided from LV feeders. Thus the number of loads does not have a significant impact.

2) The calculation of available DR by LTA is performed using statistical methods. Therefore, without any optimization involved, the time process does not rise. 
3) The load scheduling proposed in this research is based on decision-making at each time-interval individually. Hence, no optimization is required. However, even if an optimization method is applied in order to schedule the household appliances taking in to account a set of prices for a specific period, e.g., next few hours and next day, the time processing is minimal. That is because the optimization is done in parallel for each household.

4) HAs decide about their running of their shiftable appliances at real time and independently from other timeslots, thus not requiring any optimization. If an optimization technique is considered for load scheduling based on prices for a defined period, the processing time is low. This is due to the optimization being performed in parallel for all HAs.

5) The termination criteria of the optimization algorithm employed at the DSO, depends primarily on the network constraints and status. The size of the network or the number of variable parameters does not affected.

It can be concluded, based on the discussions, that the proposed MAS framework has scalability features. Integrating new agents with individual attributes is possible due to configurability of the framework. It can also provide a platform where the system layout is adjustable. Furthermore, the framework provides the possibility for goals, tasks accessibility to other participants' information to be modified during implementation. The potential to combine a centralised and decentralised control scheme can also provide added benefit. Therefore the feasibility and effectiveness of the proposed framework for applying price-based and incentive-based DR in the DN can be confirmed.

\section{Conclusion and Future Work}

This paper developed and implemented a MAS framework for active network management of distribution networks using demand response. The aim is to propose a dynamic platform as an applicable and useful tool to support the DNO transaction to DSO readiness. Deploying such a framework by DNOs, enables them to control the load flow across their network and relieve the constraints through real time pricing tariffs without costly network upgrading investment. It also benefits the other third party entities such as aggregators, suppliers and consumers to participate in DR programmes more actively. The proposed methodology employs the price-based DR from flexible residential loads which are modelled by synthetic load profiles created from historical data. Moreover, the price of electricity is individualised for each LV feeder connected to several residential loads. This models the variety behavior of customers charactristics in response to different energy suppliers and provides more dynamic and efficient framework.

Two scenarios are considered including before and after DR implementation. The simulation results showed the capability and effectiveness of the proposed DR framework in controlling the power flow equations in MV feeders. That is achieved by maintaining the network active power within the acceptable limits by reducing available flexible demands considering the most influential LV buses. The active power of the network was maintained within the acceptable limits by reducing available flexible demands considering the most influential LV buses. As an example, for feeder 7 at timeslot 37, the required DR was calculated to be $69.44 \%$ of the total available flexible demands. The DR implementation resulted in load reduction of $69.30 \%$ which indicates the feasibility of this framework. One advantage of the proposed framework is that connecting a new agent with specific attributes to the proposed system is feasible due to the configurability feature of the proposed platform. In addition, the agent's goals, tasks and accessibility to other agent's information can be modified during system 
operation. The scalability feature allows the integration of new loads, generations and agents without affecting the simplicity and computational process of the DR algorithms. This enables the integratiion of both centralised and decentralised DR control mechanism.

Future work includes merging local control by each LTA with wide area network management in order to achieve more dynamic and reliable networks. Accordingly, at each time interval, HAs optimise their appliances time scheduling by predicting and updating the price for the remaining time of the day. Applying the feedback of the HAs on changing prices the as well as Distribution Use of System (DUoS) in updating RTP is also a future interest.

\section{References}

[1] a. S. G. A. Laguna-Estopier, "Active Network Management for integrating renewable energy to the distribution network," [Online]. Available: https://innovation.ukpowernetworks.co.uk/innovation/en/Projects/tier-2-projects/FlexiblePlug-and-Play-(FPP)/Project-Documents/Wind-Integration-Workshop+2013-CA.pdf.

[2] "UK networks: Making the switch from DNO to DSO," [Online]. Available: https://www.engerati.com/article/uk-networks-switch-dno-dso-western-power-distribution. [Accessed 10 Jul. 2017].

[3] P. Siano, "Demand responseandsmartgrids-A survey," RenewableandSustainableEnergyReviews, vol. 30, p. 461-478, 2014.

[4] "Rough guide to engaging communities in energy network innovation," Regen, UK, Feb. 2017.

[5] "Customerl Load active system services second tier LCN fund addendum to project closedown report,"Electricity North West,, May. 2016..

[6] "Shetland northern isles new energy solutions (NINES) project consultation," Ofgem, Aug. 2011.

[7] W. F. C. M. a. C. S. M. Jin, "Microgrid to enable optimal distributed energy retail and end-user demand response," Applied Energy, vol. 210, p. 1321-1335, 2018.

[8] E. A. M. C. a. C. H. N. Good, "A transactive energy modelling and assessment framework for demand response business cases in smart distributed multi-energy systems," Energy, pp. 1-15, 2018.

[9] S. H. H. a. X. Z. R. Lu, "A Dynamic pricing demand response algorithm for smart grid: Reinforcement learning approach," Applied Energy, vol. 220, p. 220-230, 2018.

[10] A. R. Jordehi, "Optimisation of demand response in electric power systems, a review," Renewable and Sustainable Energy Reviews, vol. 103, p. 308-319, 2019.

[11] A. Losi, P. Mancarella and A. Vicino, Integration of demand response into the electricity chain, UK: STE Ltd, 2015. 
[12] “Demand Response Discussion for the 2007 Long-Term Reliability Assessment," The North American Electric Reliability Corporation's (NERC) mission, Oct. 2007. [Online]. Available: http://www.nerc.com/files/Itra2007.pdf.

[13] G. W. D. E. O. a. M. N. P. R. Henríquez, "Participation of Demand Response Aggregators in Electricity Markets: Optimal Portfolio Management," IEEE Transactions on Smart Grid, vol. 9, no. 5, Sept. 2018.

[14] S. W. X. Z. F. d. L. a. T. H. Z. Li, “Dynamic Demand Response Using Customer Coupons Considering Multiple Load Aggregators to Simultaneously Achieve Efficiency and Fairness," IEEE Transactions on Smart Grid, vol. 9, no. 4, JULY 2018.

[15] A.N.M.M. Haque, P.H. Nguyen, F.W. Bliek, and J.G. Slootweg, "Demand response for real-time congestion management incorporating dynamic thermal overloading cost," Sustainable Energy, Grids and Networks, vol. 10, pp. 65-74, June 2017.

[16] W. Liu, Qiuwei Wu, F. Wen, and J. Østergaard, "Day-Ahead Congestion Management in Distribution Systems Through Household Demand Response and Distribution Congestion Prices," IEEE TRANSACTIONS ON SMART GRID, vol. 5, no. 6, pp. 2739-2747, Nov. 2014.

[17] D. P. C. N. D. a. C. C. S. Behboodi, "Transactive control of fast-acting demand response based on thermostatic loads in real-time retail electricity markets," Applied Energy, vol. 210, p. 13101320, 2018.

[18] M.Shafie-khah, and Jo. P. S. Catalão, "A Stochastic Multi-Layer Agent-Based Model to Study Electricity Market Participants Behavior," IEEE Transactions on Power Systems, vol. 30, no. 2, pp. 867 - 881, March 2015.

[19] L. Gkatzikis, I. Koutsopoulos and T. Salonidis, "The Role of Aggregators in Smart Grid Demand Response Markets," IEEE Journal on Selected Areas in Communications, vol. 31, no. 7, pp. 1247 - 1257, Jul. 2013.

[20] M.M. Viyathukattuva, M.A.P.H. Nguyen, and W.L. Kling, "An integrated control for overvoltage mitigation in the distribution network," in IEEE PES Innovative Smart Grid Technologies Conference Europe, Istanbul, Turkey, 12-15 Oct. 2014.

[21] V. S. K. M. B. a. S. A. Khapard, "“A system and method for electricity price forecasting with a Novel Forecast Error Correction,"," Recent Patents on Electrical \& Electronic Engineering J., vol. 6, no. 1, pp. 29-41, 2013.

[22] M. N. a. W. K. M.M. Viyathukattuva, " "An integrated control for overvoltage mitigation in the distribution network,"," in IEEE PES Innovative Smart Grid Technologies Conference Europe, Istanbul, Turkey, 12-15 Oct. 2014..

[23] M. Wooldridge, An Introduction to Multiagents Systems, New York: Wiley, 2002.

[24] S. Howell, Y. Rezgui, J. L. Hippolyte, B. Jayan, and H. Li, "Towards the next generation of smart grids: Semantic and holonic multi-agent management of distributed energy resources," Renewable and Sustainable Energy Reviews, vol. 77, pp. 193-124, 2017. 
[25] W. Khamphanchai, M. Pipattanasomporn, M. Kuzlu, J. Zhang, and S. Rahman, "An Approach for Distribution Transformer Management With a Multiagent System," IEEE Transaction on Smart Grid, vol. 6, no. 3, pp. 1208-1218, May 2015.

[26] P. Oliveira, T.Pinto, H. Morais, and Z. Vale, "MASGriP-multi-agent smart grid simulation platform," in In Proceedings of the 2012 IEEE Power and Energy Society General Meeting, San Diego, CA, USA, 22-26 Jul. 2012.

[27] R. K. B.-J. a. J. R. P. H. Golmohamadia, "A multi-agent based optimization of residential and industrial demand response aggregators," Electrical Power and Energy Systems, vol. 107, pp. 472-485, 2019.

[28] P. Faria, J. Spínola, and Z. Vale , "Aggregation and remuneration of electricity consumers and producers for the definition of demand-response programs," IEEE Trans, vol. 12, p. 952-961, 2016.

[29] L. Gkatzikis, I. Koutsopoulos, and T. Salonidis, "The Role of Aggregators in Smart Grid Demand Response Markets," IEEE Journal on Selected Areas in Communications, vol. 31, no. 7, pp. 1247 -1257, Jul. 2013.

[30] A.S. Gazafroudi, T. Pinto, F. Prieto-Castrillo, J. M. Corchado, O. Abrishambaf, A. Jozi, and Z. Vale, "Energy flexibility assessment of a multi agent-based smart home energy system," in IEEE 17th International Conference on Ubiquitos Wireless Broadband, Spain, 2017.

[31] G. Santos, T. Pinto, I. Praça, and Z. Vale, "MASCEM: Optimizing the performance of a multiagent system," Energy, vol. 111, p. 513-524, 2016.

[32] S. Davarzani, I. Pisica, and G. A. Taylor, "Development of a Novel Multi-Agent System for Residential Voltage Control Using Demand Response based on Customer Behaviour," in IEEE International Conference on Innovative Smart Grid Technologies, IEEE ISGT Euroup, Torino, Italy, Sept. 2017.

[33] "Data Communication Company (DCC)," [Online]. Available: https://www.smartdcc.co.uk/about-dcc/. [Accessed 10 Feb. 2018].

[34] S. Davarzani, I. Pisica, and G. A. Taylor,, "A novel methodology for predicting potential responsiveness in household demand," in Int. Conf. International Conference on Resilience of Transmission and Distribution Networks (RTDN),, Birmingham, UK, Sept. 2017.

[35] S. Davarzani, I. Pisica, and G. A. Taylor, "Assessment of Residential Electricity Tariff Switching Based on Customer Response Elasticity," in 52th International universities'Power Engineering Conferance(UPEC), Crete, Greece, Sept. 2017.

[36] B. Bakhshideh Zad, H. Hasanvand, J. Lobry, and F. Vallée, "Optimal reactive power control of DGs for voltage regulation of MV distribution systems using sensitivity analysis method and PSO algorithm," Electrical Power and Energy Systems, vol. 68, pp. 52-60, 2015.

[37] A. Augugliaro, L. Dusonchet, S. Favuzza, M.G. Ippolito, and E. R. Sanseverino, "A backward sweep method for power flow solution in distribution networks," Electrical Power and Energy Systems, vol. 32, p. 271-280, 2010. 
[38] J. R. Schofield, Dynamic time-of-use electricity pricing for residential demand response: Design and analysis of the Low Carbon London smart-metering trial, London, Uk: PhD thesis, Imperial College London, 2015.

[39] “EDF Energy," [Online]. Available: https://www.edfenergy.com. [Accessed Dec. 2017].

[40] S. Deilami, A. S. Masoum, P. S.Moses, and M. A. S. Masoum, "Real-time coordination of plug-in electric vehicle charging in smart grids to minimize power losses and improve voltage profile," IEEE Trans. Smart Grid, vol. 2, no. 3, pp. 456-467, Sep. 2011.

[41] D. Zhang, Z. Fu, and L. Zhang, "An improved TS algorithm for loss-minimum reconfiguration in large-scale distribution systems," Electric Power Systems Research, vol. 77, pp. 685-694, 2007.

[42] "Data from the Commission for Energy Regulation (CER) - smart metering project," Irish Social Science Data Archive, 2702 2017. [Online]. Available:

http://www.ucd.ie/issda/data/commissionforenergyregulationcer/.

[43] R. Granell, C. J.Axon, and D. C.H.Walloma, "Clustering disaggregated load profiles using a Dirichlet process mixture model," Energy Conversion and Management, vol. 92, pp. 507-516, March 2015.

[44] J. Jargstorf, K. Vanthournout, T. De Rybel, and D. Van Hertem, "Effect of demand response on transformer lifetime expectation," in Proc. 3rd, Berlin, Germany, Oct. 2012,.

[45] N. Efkarpidis, C. Gonzalez, and T. Wijnhoven, "Technical assessment of on-load tap-changers in flemish LV distribution grids,"," in Proc. 3rd Solar Integr. Workshop, London, U.K., Oct. 2013.

[46] Z. Csetvei, J. Ostergaard, and P. Nyeng, "Controlling price responsive heat pumps for overload elimination in distribution system," in roc. 2nd IEEE PES Int. Conf. Exhibit. Innov. Smart Grid Technol. (ISGT Europe), Manchester, U.K., Dec. 2011.

[47] P. Richardson, D. Flynn, and A. Keane, "Optimal charging of electric vehicles in low-voltage distribution systems," IEEE Trans. Power Syst., vol. 27, no. 1, p. 268-279, Feb. 2012..

[48] C. Molitor, F. Ponci, A. Monti, D. Cali, and D. Muller, "Consumer benefits of electricity-pricedriven heat pump operation in future smart grids," in in Proc. IEEE Int. Conf. Smart Meas. Future Grids (SMFG), Bologna, Italy, Nov. 2011.

[49] S. Pfaffen, K. Werlen, and S. Koch, "Evaluation of business models for the economic exploitation of flexible thermal loads," in in Proc. 39th Annu. Conf. IEEE Ind. Electron. Soc. (IECON), Vienna, Austria, Nov. 2013.

[50] S. Nykamp et al., "Integration of heat pumps in distribution grids: Economic motivation for grid control," in Oct. 2012, Berlin, Germany, in Proc. 3rd IEEE PES Int. Conf.Exhibit. Innov. Smart Grid Technol. (ISGT Europe).

[51] A. Abdisalaam, I. Lampropoulos, J. Frunt, G. P. J. Verbong, and W. L. Kling, "Assessing the economic benefits of flexible residential load participation in the Dutch day-ahead auction and balancing market," in in Proc. 9th Int. Conf. Eur. Energy Market (EEM), Florence, Italy, May 2012. 
[52] Y. Omagari, H. Sugihara, K. Tsuji, and T. Funaki, "An economic effect of demand response with thermal storage air-conditioning systems in electricity markets," in Sep. 2009, Valencia, Spain, in Proc. IEEE PES/IAS Conf. Sustain. Altern. Energy (SAE).

[53] N. Etherden, and M.H.J. Bollen, "Overload and overvoltage in low-voltage and medium-voltage networks due to renewable energy-some illustrative case studies," Electr. Power Syst. Res., vol. 114, pp. 39-48, Sept. 2014.

[54] S. You, and H. Segerberg, "Integration of 100\% micro-distributed energy resources in the low voltage distribution network: A Danish case study," Appl. Therm. Eng., vol. 71, no. 2, pp. 797808, Oct. 2014.

[55] S. Shao, M. Pipattanasomporn, and S. Rahman, “An Approach for Demand Response to Alleviate Power System Stress Conditions," in Proc. IEEE Power Energy Soc. Gen. Meeting, San Diego, CA, USA, 2011.

[56] W. Liu, Q. Wu, F. Wen, and J. Østergaard, "Day-ahead congestion management in distribution systems through household demand response and distribution congestion prices," IEEE Transactions on Smart Grid, vol. 5, no. 6, pp. 2739 - 2747, July 2014.

[57] A.N.M.M.Haque, P.H.Nguyen, F.W. Bliek, and J.G.Slootwega, "Demand response for real-time congestion management incorporating dynamic thermal overloading cost," Sustainable Energy, Grids and Networks, vol. 10, pp. 65-74, June 2017.

[58] A.N.M.M. Haque, M. T. Rahman, P.H. Nguyen, and F.W. Bliek, "Smart curtailment for congestion management in LV distribution network," in Power and Energy Society General Meeting (PESGM), Boston, MA, USA, 17-21 Jul. 2016.

[59] S. Shao, M. Pipattanasomporn, and S. Rahman, "Grid integration of electric vehicles and demand response with customer choice," IEEE Transactions on Smart Grid, vol. 3, no. 1, pp. 543 - 550, March 2012.

[60] M. Pipattanasomporn, M. Kuzlu, and S. Rahman, “An algorithm for intelligent home energy management and demand response analysis," IEEE Transactions on Smart Grid, vol. 3, no. 4, pp. 2166-2173, 2012.

[61] J. Mathieu, M. Dyson, and D. Callaway, "Using residential electric loads for fast demand response: The potential resource and revenues, the costs, and policy recommendations," ACEEE Summer Study on Energy Efficiency in Buildings, pp. 189-203, 2012.

[62] Elexon, "Load Profiles and their use in Electricity Settlement," Available:https://www.elexon.co.uk/knowledgebase/profile-classes, Last seen: Jul. 2015.

[63] G. Grigoras, G. Cartina, E.C. Bobric and C. Barbulescu, "Missing Data Treatment of the Load Profiles in Distribution," in IEEE Bucharest Power Tech Conference, Bucharest, Romania, 2009.

[64] A. Mutanen, M. Ruska, S. Repo, P. Jarventausta, "Customer classification and load profiling method for distribution systems," IEEE Transaction on Power Delivery, vol. 26.3, Jul. 2011. 
[65] B. Hayes, I. Hernando-Gil, A. Collin, G. Harrison, and S. Djokić, “Optimal power flow for maximizing network benefits from demand-side management," IEEE Transactions on Power Systems, vol. 29, no. 4, pp. 1739-1747, Jul. 2014.

[66] "The future of demand response in electricity distribution," Accenture, 2016.

[67] S. CHEN, and C.C. LIU, "From demand response to transactive energy: state of the art," J. Mod. Power Syst. Clean Energy, vol. 5, no. 1, pp. 10-19, 2017.

[68] S. Davarzani, I. Pisica and G. Taylor, "Development of a Novel Multi-Agent System for Residential Voltage Control Using Demand Response based on Customer Behaviour," in IEEE ISGT Europe, Torino, Italy, 26-29 Sept.2017.

[69] S. Davarzani, I. Pisica, L. Lipan,, "Novel model for defining electricity tariffs using residential load profile characterisation," International Journal of Renewable Energy Technology, 13 Feb. 2018 (Accepted).

[70] Newquay Weather Station, [Online]. Available: http://www.newquayweather.com/wxsolarpvlog.php. [Accessed 2004 2018].

[71] C. W. T. X. L. G. P. L. L. Y. a. H. M. X. Wanga, “Optimal voltage regulation for distribution networks with multi-microgrids," Applied Energy, vol. 210 , p. 2018, 1027-1036. 